\title{
Pedagogia da alternância e a formação de educadores/as: a experiência do programa girassol
}

\author{
Pedagogy of alternance and educator training: the sunflower program \\ experience \\ Celso Eulálio de Oliveira Júnior \\ Alcione Reetz
}

Resumo: Os educadores/as se constituíram como significativos sujeitos para a construção e fortalecimento da Pedagogia da Alternância e Educação do Campo. Contudo a formação desses profissionais ainda é um desafio a ser superado por esse movimento. Dessa forma, o objetivo deste trabalho foi caracterizar a formação dos educadores/as da Pedagogia da Alternância, através da experiência do Programa Girassol de formação continuada para atuar na Pedagogia da Alternância e Educação do Campo no município de Nova Venécia, Espírito Santo. Para sistematizar essa experiência, utilizamos a pesquisa qualitativa, documental, nos referenciando em Nosella (2014; 2007) e Begnami (2003). Utilizamos ainda a observação participante natural, na forma expressa por Gil (2008). Constatamos que, apesar dos avanços em relação a formação dos educadores/as que atuam na Pedagogia da Alternância e Educação do Campo no município, ainda persiste uma situação desafiadora em relação a essa que ameaça a continuidade dessa proposta, sendo necessárias ações para garantir e fortalecer a formação dos educadores/as que atuam nessa modalidade.

Palavras-chave: Programa Girassol, Formação de Educadores/as, Pedagogia da Alternância.

Abstract: Educators were constituted as significant subjects for the construction and strengthening of Pedagogy of Alternation and Rural Education. However, the training of these professionals is still a challenge to be overcome by this movement. Thus, the objective of this work was to characterize the education of educators of Pedagogy of Alternation, through the experience of the Girassol Program of continuing education to work in Pedagogy of Alternation and Rural Education in the municipality of Nova Venécia, Espírito Santo. To systematize this experience, we used qualitative, documentary research, referencing us in Nosella (2014; 2007) and Begnami (2003). We also use natural participant observation, as expressed by Gil (2008). We note that, despite advances in the training of educators who work in Pedagogy of Alternation and Rural Education in the municipality, a challenging situation still exists in relation to the one that threatens the continuity of this proposal, requiring actions to guarantee and strengthen the training of educators who work in this modality.

Keywords: Girassol Program, Educator Training, Pedagogy of Alternation.

\section{Introdução}

A Pedagogia da Alternância, desde sua origem no Brasil em 1969, tem se expandido cada vez mais nesse país, alcançando em 2017 a marca de 296 escolas (OLIVEIRA, 2018). Essa dinâmica pedagógica, busca através de seus princípios e instrumentos pedagógicos, contribuir com a emancipação e a 
transformação das pessoas e do meio, exigindo para isso o conhecimento da realidade, devendo, portanto, considerar o ser humano, um ser de relações que não apenas está no mundo, mas, também, com o mundo, assim como afirma Freire (2013).

Para que a Pedagogia da Alternância se constituísse dessa forma e como uma importante dinâmica pedagógica no município de Nova Venécia, Espírito Santo, foi necessário grande engajamento dos parceiros da formação, que se referem aos estudantes, suas famílias, os educadores/as e outros colaboradores/as que ajudam nessa construção.

Nos Centros Familiares de Formação em Alternância (Ceffa's) os educadore/as, são denominados de monitores/as. Eles recebem essa denominação para se diferenciarem da função exercida pelos professores, tendo eles, conforme Gimonet (2007) e Begnami (2003), função mais ampla e complexa que os professores, como veremos nesse trabalho. Contudo, a denominação de monitor/a, na forma mais habitual do termo, traz muitas confusões em relação a função exercida por esses profissionais, como nos explica Nosella (2014). Desse modo, adotaremos nesse trabalho a nomenclatura educador/a para nos referirmos aos monitores dos Ceffa's, tendo em vista que evita as confusões do termo, ao mesmo tempo que expressa, na perspectiva apresentada por Freire (2013), o mesmo sentido de monitor.

Diante da forte integração existente entre os parceiros da formação, tornase muito difícil analisá-los separadamente. Contudo, a situação dos educadores/as tem se demonstrando mais desafiadora no contexto desse município, especialmente no que tange aos processos de formação continuada para possibilitar a esses profissionais a preparação necessária para atuar nessa modalidade de educação.

Dessa forma, neste trabalho aprofundaremos a análise dessa problemática com o intuito de conhecer mais detalhes sobre essa situação e caracterizar a formação dos educadores/as da Pedagogia da Alternância no município de Nova Venécia, através da experiência do Programa Girassol de formação continuada para atuar na Pedagogia da Alternância e Educação do Campo. 
Para tanto, inicialmente, após apresentar nosso caminho metodológico, caracterizamos a importância e função dos educadores/as que atuam nos Ceffa's. Em seguida contextualizamos a Pedagogia da Alternância no município de Nova Venécia, encerrando com a caracterização da experiência do Programa Girassol.

\section{O caminho metodológico}

Nesta pesquisa foi analisada a experiência de formação de educadores/as para atuar na Pedagogia da Alternância e Educação do Campo no município de Nova Venécia, Espírito Santo. A motivação para esse estudo esteve fundada na importância da Pedagogia da Alternância e Educação do Campo para o município, tendo sido a formação de educadores/as um limitante a essas escolas, ao longo de sua existência, sendo necessário investigar os desafios, mas também as possibilidades para ajudar a superar ou ao menos minimizar essa problemática, fortalecendo essa modalidade de ensino, o campo e os camponeses/as presentes nesse território.

Para a realização da pesquisa, foi utilizada uma abordagem qualitativa do tipo aplicada e a estratégia adotada foi a sistematização da experiência. A pesquisa em educação busca não apenas identificar problemas e fazer análises, mas também estimular a transformação da realidade estudada.

O objetivo do trabalho foi caracterizar a formação dos educadores/as da Pedagogia da Alternância no município de Nova Venécia, através da experiência do Programa Girassol de formação continuada para atuar na Pedagogia da Alternância e Educação do Campo.

Como procedimento metodológico, utilizamos a pesquisa bibliográfica e documental, relativos a formação de educadores/as para atuar na modalidade Educação do Campo e especificamente os relacionados ao Programa Girassol. Além disso, adotamos a observação participante natural, apontada por Gil (2008), como muito útil quando os pesquisadores fazem parte do grupo estudado, possibilitando investigá-lo a partir do seu interior, sendo justificado nesse caso pela participação dos autores no processo de articulação, elaboração e operacionalização do programa. 


\section{Pedagogia da Alternância e formação de educadores/as: necessidades e desafios}

Os Ceffa's são escolas que adotam a Pedagogia da Alternância, possuindo dinâmica pedagógica apropriada ao território onde estão inseridas. Através da alternância, entre tempo-espaço, eles articulam diversos instrumentos pedagógicos, que amplamente integrados a participação das famílias e de outros parceiros da comunidade escolar, promovem formação contextualizada, buscando construir uma educação libertadora e emancipadora, na perspectiva de Freire (2013).

Essas escolas possuem identidade da Educação do Campo, ou seja, consistem em ser:

um projeto de educação que reafirma, como grande finalidade da ação educativa, ajudar no desenvolvimento mais pleno do ser humano, na sua humanização e inserção crítica na dinâmica da sociedade que faz parte; que compreende que os sujeitos se humanizam ou se desumanizam sob condições materiais e relações sociais determinadas; que nos mesmos processos em que produzimos nossa existência nos produzimos como seres humanos; que as práticas sociais e, entre elas, especialmente as relações de trabalho conformam (formam ou deformam) os sujeitos (CALDART, 2002, p. 22).

A Educação do Campo, com base em Caldart (2012), se diferencia da Educação para o Campo, pois a primeira se refere a educação como um direito dos camponeses/as, sendo construída no bojo da luta histórica dos povos do campo, com a sua participação e partir do seu território, carregando os seus valores, a sua identidade. Enquanto a Educação para o Campo, se trata, de modo geral, de uma educação pensada com base na visão urbanocêntrica e estendida ao campo, como uma política compensatória.

Historicamente, a Pedagogia da Alternância foi construída com particularidades em relação aos projetos de educação hegemônicos. No Brasil, ela inicia sua jornada no período da ditadura militar, com severas limitações determinadas por esse contexto, mas realizando um trabalho de promoção social conseguiu se estabelecer e expandir, inicialmente, no território capixaba e posteriormente pelo Brasil (NOSELLA, 2014). 
Desse modo, a Pedagogia da Alternância se constituiu como uma pedagogia revolucionária, se contrapondo a perspectiva violenta de expulsar ou fixar o homem no campo, estimulando a mudança nas relações campo-cidade e a transformação da realidade por meio da formação dos sujeitos do campo.

Para que a Pedagogia da Alternância se consolidasse como uma importante dinâmica pedagógica, foi necessário grande engajamento dos educadores/as, se constituindo como importantes parceiros na construção e desenvolvimento do movimento Ceffa pelo mundo. Para França e Burghgrave (2007), eles são os sujeitos animadores, articuladores de todo o projeto, tendo papel crucial para as escolas da Alternância alcançarem seus objetivos.

Diante da importância desses profissionais é que sua função tem sido sistematizada e aperfeiçoada ao longo da história desse movimento, sendo que algumas características básicas permanecem desde a origem dessa categoria na França. Contudo, essa elaboração não tem sido uma tarefa fácil, pois diante da complexidade e abrangência da atuação desse profissional, aliado a natureza dialética dessa profissão, se ajustando ao período-histórico em que se realiza e as características locais que cada escola confere a ela, encontra-se uma grande dificuldade para definir precisamente a sua função.

Procurando caracterizar a atribuição desse profissional no Ceffa, num sentido político-pedagógico da atuação, Nosella (2007), afirma o caráter revolucionário dessa pedagogia, buscando a transformação das relações campo-cidade, esclarecendo ainda que o educador/a que atua nesse projeto precisa construir um perfil e uma atuação nessa mesma direção, tornando-se,

[...] revolucionário quando cumpre sua função pedagógica, porque traz na sua concepção metodológica e científica a potencialidade de transformar profundamente as relações sociais no campo. Portanto, esse educador é um profissional militante, mesmo quando não exerce formalmente militância política (NOSELLA, 2007, p.15).

Nesse sentido, sobre a competência desse profissional, esse mesmo autor afirma que:

Não existe um educador competente que não realize em seu ato político pedagógico uma determinada militância política. [...] a Pedagogia da Alternância é uma técnica didática que efetiva 
uma opção política progressista, renovadora e revolucionária. Por isso, ao praticar com competência essa pedagogia, ao mesmo tempo milita-se politicamente numa direção revolucionária (NOSELLA, 2007, p. 6).

Em uma dimensão mais pedagógica, mas não se esquecendo do papel político desse profissional, Gimonet (2007), propõe que ele tenha os seguintes papéis: de educação, pedagógicos, relação de animação e técnico.

Nesse mesmo sentido, para a Regional das Associações dos Centros Familiares de Formação em Alternância do Espírito Santo (Raceffaes), as dimensões desse profissional que atua nos Ceffa's são basicamente sete e cada uma delas se relaciona com uma função do educador/a na Pedagogia da Alternância, a saber: a) acompanhamento de turma e do dia: a vida ensina mais que a escola; b) administração das disciplinas: método sobre o conhecimento; c) funções de coordenação: trabalho em equipe; d) administração de tarefas: corresponsabilidade; e) funções externas: movimento de educação (RACEFFAES, 2010).

Por sua vez, Begnami (2003) assevera que as peculiaridades dessa pedagogia, fará com que o educador/a precise, paradoxalmente, assumir um perfil diferente do adotado nas escolas em geral. Ele esclarece que esse profissional possui um papel mais amplo que o do professor, devendo ser um articulador, animador dos vários processos do Ceffa, integrando os vários parceiros da formação. Na verdade, ele deve superar a perspectiva de professor, e à medida que caminha em sua práxis, ir se transformando em educador/a, sendo a polivalência um requisito fundamental para o sucesso em seu trabalho, contribuindo para os Ceffa's alcançarem sua finalidade.

Assim, ele afirma que o educador/a na Pedagogia da Alternância trata de:

[...] um agente de comunicação entre os diferentes atores e instâncias da EFA. A capacidade de animação e comunicação é indispensável para uma atividade exitosa e participativa, onde todos assumam seus papéis responsavelmente, fazendo sua parte na complementariedade da formação (BEGNAMI, 2003, p. 51).

Com base no exposto fica evidente a importância do parceiro educador/a para o Ceffa e para viabilizar a proposta educativa dessa pedagogia, sendo difícil 
construir uma escola com dinâmica pedagógica tão complexa, com uma função simplificada desse profissional.

Para alcançar o perfil desejável de educador/a dessa pedagogia, é necessário, além do tempo de trabalho e vivência da Educação do Campo e do Campo, uma boa formação teórica, sendo ainda essa questão um dos grandes desafios a ser superado por esse coletivo, tendo em vista que ainda hoje, não são comuns cursos superiores que promovam esse tipo de formação, apesar dos notáveis avanços principalmente com a Licenciatura em Educação do Campo.

Segundo Arroyo et al. (2008), em geral os programas de formação de educadores/as, sobretudo as graduações, não abordam a Educação do Campo, ou se fazem é no sentido de reproduzir preconceitos e abordagens pejorativas, estando os currículos fundamentados quase que exclusivamente para contextos urbanos.

Desse modo, para Leonarde e Simões, (2015, p. 1664), "quando pensamos na formação docente em contextos campesinos, logo pensamos em uma formação comprometida com a transformação consciente da realidade escolar, da complexidade e desafios que emergem desse/nesse campo." Contudo, ainda segundo esses mesmos autores, muitos educadores/as que atuam nas escolas do campo, não possuem formação adequada para essa modalidade, tendo dificuldade para lidar com as peculiaridades da região, tendo muitos empecilhos para se inserirem em processos de formação continuada (LEONARDE; SIMÕES, 2015).

Por todas essas questões e aliadas a outras relacionadas a valorização e reconhecimento da necessidade desse profissional, fizeram com que a questão dos educadores/as se constituíssem como um desafio a esse movimento, sendo essa categoria, ao mesmo tempo, um impulsionador e um limitador do desenvolvimento do Ceffa, havendo uma nítida preocupação histórica com a formação desse coletivo, em vista de alcançar os ideais da formação dessa pedagogia (OLIVEIRA JÚNIOR, 2019).

Essa dificuldade em relação a formação dos educadores/as, não tem sido uma particularidade do cenário atual da Pedagogia da Alternância no Brasil, na 
verdade, ela remonta a sua origem na França (NOSELLA, 2014; GIMONET, 2007) e no Brasil (NOSELLA, 2014; BEGNAMI, 2003), sendo desenvolvidas muitas experiências e tentativas de promover espaços de formação para ajudar a minimizar esses desafios e avançar na construção da Pedagogia da Alternância, fortalecendo a Educação do Campo no estado do Espírito Santo.

No âmbito estadual, algumas instituições e organizações, tem assumido importante papel nessa construção, com destaque para o Movimento de Educação Promocional do Espírito Santo (Mepes), que desde 1971, estabeleceu - Centro de Formação e Reflexão de Monitores/as (NOSELLA, 2014); a Raceffaes, que desde 2003, tem atuado no estado promovendo a unidade e o fortalecimento dos Ceffa's e a Educação do Campo (RODRIGUES, 2019); o Movimento de Trabalhadores e Trabalhadoras Rurais Sem Terra (MST), com destaque para os cursos de Pedagogia da Terra (FOERSTER, 2005).

A rede federal de ensino também tem contribuído com a oferta de formação à Educação do Campo, seja individualmente ou em parceria com os movimentos sociais do campo, como é o caso de alguns campi do Instituto Federal do Espírito Santo, que promoveram seminários e cursos de aperfeiçoamento em Agroecologia, Pedagogia da Alternância e Educação do Campo, como também especialização nessas mesmas áreas; a Universidade Federal do Espírito Santo, com curso de aperfeiçoamento, mas principalmente, a nosso ver, com a oferta desde 2014, do curso de Licenciatura em Educação do Campo (LEONARDE; SIMÕES, 2015). Sendo esse, uma antiga demanda dos movimentos e organizações sociais do campo, sobre o qual projeta grandes expectativas para ajudar a avançar na formação de educadores/as para atuar na Pedagogia da Alternância e Educação do Campo.

Além dessas, encontramos ainda o registro de atividades ofertadas pelas faculdades particulares, com cursos de especialização em Educação do Campo.

Apesar dessas importantes iniciativas, elas ainda não são suficientes para resolver a questão da formação dos educadores/as para atuar na Pedagogia da Alternância e Educação do campo, até porque esse desafio não se dá de maneira isolada, sendo necessário superar outras questões para possibilitar 
ainda mais avanços, como a questão do reconhecimento e valorização dessa profissão, garantia de contratação em editais específicos etc.

Diante desse contexto, urge a necessidade da qualificação de educadores/as para atuar na Pedagogia da Alternância e Educação do Campo, com destaque para além dos cursos de graduação, a necessidade de criar programas de "formação cujas metodologias permitam a vivência de novas alternativas pedagógicas no próprio processo de formação. Emerge a necessidade da formação de professores com visão do mundo do campo, com uma formação específica para a área rural" (LEONARDE; SIMÕES, 2015, p. 11665).

Assim, permanece atual a necessidade do coletivo da Educação do Campo seguir construindo e reivindicando ações para superar esse desafio, desenvolvendo e divulgando iniciativas e experiências de formação e buscando assegurar esse direito como política pública, como afirma Arroyo (2007). Nesse sentido, nos títulos que seguem, buscaremos apresentar a experiência desenvolvida em Nova Venécia, buscando superar a problemática aqui apresentada.

\section{A formação de educadores/as da Pedagogia da Alternância no contexto do município de Nova Venécia}

O contexto de Nova Venécia em relação a formação de educadores/as, não difere muito do contexto geral, apresentado anteriormente, persistindo desafios muito semelhantes.

De modo geral, analisando o processo histórico de constituição da Pedagogia da Alternância no município, constatamos, em relação as experiências de formação de educadores/as, a existência de dois grandes períodos, que denominamos de pré e pós-expansão da Pedagogia da Alternância. O período pré-expansão, vai de 1988, ocasião da implantação da Escola Família Agrícola de Chapadinha (Efac), até 2008, quando definiu-se pela implantação das Escolas Municipais Comunitárias Rurais (Emcor's).

Nesse primeiro período, a formação foi destinada a única escola de Pedagogia da Alternância do município, ou seja, aos educadores/as da Efac, que 
participavam quase exclusivamente das atividades de formação promovidas pelo Mepes e pela Organização de Monitores/as das Escolas Famílias Agrícolas do Norte (Omefan), atualmente denominada Associação de Monitores/as das Escolas Família Agrícola do Mepes (Amefam), que além de articular os educadores/as, também promovia formação política e pedagógica a esse coletivo (OLIVEIRA JÚNIOR, 2019).

A partir de 2003, com a criação da Raceffaes, as possibilidades de formação ficaram ainda mais diversificadas e abrangentes, pois a regional estruturou um forte projeto para construir a unidade pedagógica entre os Ceffa's, adotando a formação como o principal meio para alcançar esse objetivo (OLIVEIRA JÚNIOR, 2019). Assim, por meio dessas três vias principais os educadores/as se formavam para atuar na Pedagogia da Alternância.

O segundo período, que aqui chamamos de pós-expansão, inicia-se com a criação das Emcor's em 2009 e alcança os dias de hoje.

Para iniciar o trabalho das Emcor's foi necessário superar muitos obstáculos, tanto políticos, quanto de infraestrutura e, apesar da forte mobilização das famílias, junto à Prefeitura municipal de Nova Venécia (PMNV) e Secretaria Municipal de Educação (Seme), possibilitando superar essas situações, ainda persistia a questão dos educadores/as, pois não havia no município pessoas em quantidade suficiente, com experiência e formação específica sobre Pedagogia da Alternância, com condições de iniciar o trabalho dessas escolas, sendo essa uma ameaça ao início das atividades previstas em 2009.

Diante dessa situação, a comissão de expansão conseguiu garantir junto a Seme, a realização, ainda em 2008, de um curso sobre Pedagogia da Alternância para os interessados em atuar nas Emcor's. Contudo, por ocasião dos critérios estabelecidos no edital de contratação dos educadores/as, nem todos/as os aprovados/as tinham essa formação, aumentando os desafios iniciais dessas escolas e ameaçando a qualidade e a continuidade do trabalho (EFAC, 2010). 
Desse modo, desde o início da experiência, em virtude das diferentes normas das mantenedoras (Mepes e PMNV), as possibilidades de formação se deram, de forma heterogênea, entre a Efac e as Emcor's.

Por possuir maior autonomia, em nosso estudo verificamos que os educadores/as da Efac, continuaram participando das formações promovidas pela Raceffaes, Amefam, Mepes, Seme, mas também as da Universidade Federal do Espírito Santo (Ufes) e do Instituto Federal do Espírito Santo (Ifes), não enfrentando, em geral, problemas de liberação para isso, sendo inclusive uma política da escola o incentivo a formação nos espaços coletivos, mas também individuais. Os desafios para esse grupo estavam em concretizar essa política em nível de pós-graduação stricto sensu, não tendo ainda, uma política evidente sobre como oportunizá-la aos educadores/as, mas sendo incentivada a sua prática e encontrado alternativas específicas para cada caso.

Por outro lado, a situação dos educadores/as das Emcor's, sempre foram muito diferentes e desafiadoras, enfrentando, ao longo desses onze anos, constantes mudanças na política de formação, determinadas pelo projeto de educação de cada gestão municipal.

Dessa maneira, mesmo sendo facultado a esse coletivo as mesmas oportunidades de formação da Efac, constatamos que a possibilidade efetiva de participar delas variou conforme as diretrizes da Seme, sendo que em alguns períodos houve maior facilidade em participarem das formações externas, enquanto em outros foram mais difíceis.

Analisando os conteúdos programáticos das formações com participação das Emcor's, pode-se observar grande variação em relação aos enfoques delas, sendo que, nos períodos que puderam ter maior envolvimento, sobretudo nas ações da Raceffaes, tiveram maior amplitude de temas relacionados aos aspectos administrativos, pedagógicos e agropecuários do Ceffa, viabilizados por meio de seminários, encontros, reuniões, oficinas, cursos etc.

Em períodos de menor participação, verificamos que a formação basicamente ficou limitada a formação inicial, para os educadores/as que estivessem iniciando na Pedagogia da Alternância, ofertada pela Raceffaes e aos seminários municipais de Educação do Campo, promovidos pela Seme, 
Emcor's, Efac, Comitê de Educação do Campo de Nova Venécia (Comec-NV) e Raceffaes, sendo muito importante para esse coletivo, principalmente nos aspectos políticos, mas não sendo suficiente para atender a demanda apresentada.

Também notamos que apenas em alguns poucos períodos, não houve a possibilidade de realização de nenhuma atividade de formação para esse coletivo da via pública, sendo viabilizada apenas a formação oferecida pela rede, não tratando especificamente da Educação do Campo. A exceção para os iniciantes, a quem sempre foi possível viabilizar a participação na formação da Raceffaes para esse grupo, por meio da articulação das Emcor’s com a Seme.

Em virtude desse contexto, as escolas da Pedagogia da Alternância, sempre mantiveram a reivindicação a esse direito, mas como vimos, nem sempre foi possível alcançá-lo, fazendo com que esse coletivo encontrasse alternativas para minimizar essa ausência

Nesses períodos, foi possível observar, que a estratégia utilizada, esteve em aproveitar a experiência dos educadores/as da Efac e das próprias Emcor's e potencializar a formação interna desse coletivo, principalmente através de reuniões e oficinas, tratando principalmente de aspectos que se apresentavam como mais desafiadores ao desenvolvimento do trabalho nas Emcor's, como também possibilitando a integração e organização coletiva das escolas.

Buscando construir e oportunizar experiências de formação, para os educadores/as atuarem na Pedagogia da Alternância e Educação do Campo, é que o coletivo chegou ao Programa Girassol, como veremos em detalhes a seguir.

\section{A experiência do Programa Girassol para formação de educadores/as para atuar na Pedagogia da Alternância e Educação do Campo em Nova Venécia}

Tendo em vista as inconsistências em relação a formação de educadores/as para atuar na Pedagogia da Alternância e Educação do Campo na rede pública do município de Nova Venécia e diante da histórica reinvindicação desse direito, feito pelas Emcor`s, Efac, Comec-NV e o interesse manifestado nos seminários municipais de Educação do Campo, através do 
diálogo, entre a Seme e o coletivo da Educação do Campo, se construiu a proposta do Programa Girassol de formação continuada.

O Programa Girassol consistiu em uma proposta contínua de formação para educadores/as atuarem na Pedagogia da Alternância e Educação do Campo,

oportunizando a formação de professores, aqui entendidos como educandos (as) - educadores (as) do campo, a partir de uma nova visão de educação que comporta a abordagem de um novo currículo e novas metodologias, pautadas na realidade do campo e no interesse dos sujeito (PPP, 2018, p. 02).

O curso foi ofertado pela Seme, mas com a gestão compartilhada com as organizações da Educação do Campo do município e região, incluindo logo no início da formação a representação dos próprios cursistas nesse processo. Para isso, foi estabelecido uma comissão político-pedagógico, formada por representantes de cada um dos segmentos, que se reuniam periodicamente para preparar e gerir a formação.

De acordo com o Projeto Político-Pedagógico (PPP, 2018), o número de turmas por ano, variaria com base na demanda e condições da Seme em garantir a oferta. Dessa forma, se esperava garantir aos educadores/as acesso a essa formação, certificação e valorização nos editais de contratação dos docentes das escolas do campo, buscando fortalecer esse coletivo e o acesso aos povos do campo ao direito a educação apropriada aos seus contextos.

Outra preocupação na construção desse programa, foi oportunizar o direito a participação de educadores/as da rede que não atuassem especificamente na Educação do Campo, uma vez que é comum, em função da contratação por meio de designação temporária, que haja constante migração dos educadores/as entre escolas do campo e cidade.

Nesse sentido, uma certa novidade, pois até então as formações estavam restritas às pessoas que atuavam nessa modalidade, não sendo possível a participação dos que atuavam em escolas da zona urbana. Também foi facultado a participação de técnicos da Seme.

Com base nessas expectativas, estabeleceu-se como objetivo geral para o curso: 
Capacitar educadoras e educadores das Escolas Municipais Comunitárias Rurais de Nova Venécia (EMCOR's Nova Venécia), técnicos da Secretaria Municipal de Educação, para atuarem no processo de formação dos jovens na modalidade Educação do Campo e Pedagogia da Alternância (PPP, 2018, p. 02).

Os objetivos específicos, por sua vez foram definidos como:

- Refletir sobre o contexto sócio-histórico do campo, bem como o conceito e concepções da Educação do Campo e Pedagogia da Alternância;

- Refletir teoricamente sobre os fundamentos e as práticas da Pedagogia da Alternância na rede pública municipal de Educação;

- Discutir, exercitar e criar orientações práticas sobre as estratégias metodológicas da Pedagogia da Alternância (PPP, 2018, p. 02).

Para a construção do programa, tendo em vista que grande parte dos educadores/as que atuavam na Educação do Campo no município, não possuíam experiência nessa modalidade e buscando potencializar a experiência o máximo possível, a opção metodológica foi baseá-lo na própria Pedagogia da Alternância, possibilitando aos educadores/as uma formação sobre as ferramentas metodológicas abordadas no programa, fundamentada na experiência teórica e prática.

Para o estudo dos temas, adotou-se o método do Plano de Estudo, principal método da Pedagogia da Alternância e que permite, dentre outras funções, realizar o diagnóstico de situações diversas, possibilitando que a formação fosse aberta como "uma pesquisa empírica sobre o desdobramento do tema no cotidiano da escola" (PPP, 2018, p. 02). Além disso, também foi adotado a leitura de textos que foram fornecidos previamente pelo assessor/a de cada módulo.

Nesse sentido, os encontros foram organizados em sessão (período presencial da formação) e estadia (período em que estavam no meio socioprofissional), ofertado num conjunto de cinco módulos, com doze horas cada, sendo oito horas de tempo presencial na sessão e quatro horas de tempo comunidade, no meio socioprofissional do educador/a. Toda essa carga horária 
foi valorizada e certificada, totalizando sessenta horas de formação. (PPP, 2018).

O tempo presencial, foi aproveitado para as aulas teóricas, trocas de experiências e debates com o coletivo em formação. Já o tempo da estadia, foi disponibilizado para analisarem sua prática profissional e refletirem sobre formas de inovar, avançando na transformação da escola no, para do campo.

Em relação ao conteúdo, abordou-se os temas considerados essenciais e abrangentes aos interesses dos iniciantes e foram definidos com base na experiência da Raceffaes de formação inicial de educadores/as para atuar na Pedagogia da Alternância e Educação do Campo.

Com base na (PPP, 2018), os cinco módulos foram organizados abrangendo os seguintes temas de estudo: a) introdução à Educação do Campo e Pedagogia da Alternância; b) o método Plano de Estudo; c) o plano de formação na Pedagogia da Alternância; d) auto-organização dos estudantes, educadores e famílias; e) instrumentos da Pedagogia da Alternância. Fechando toda essa formação, foi realizado o $5^{\circ}$ encontro, que consistiu no $4^{\circ}$ Seminário de Educação do Campo do município de Nova Venécia, com o tema: A Educação do Campo e o Desenvolvimento de nossa Região (PMNV, 2015).

Para gerir o curso, com base no estabelecido na PPP (2018), foi adotado a auto-organização, sendo distribuído o coletivo em três grupos: a) mística e ornamentação, responsável por meio de símbolos, e expressões artísticas, como encenação, leitura de poema, cantoria etc, trazer no início e termino de cada encontro a importância, a expectativa, os aprendizados do tema abordado no encontro e da mesma forma ao final; b) secretaria, responsável por todos os registros, materiais e equipamentos didáticos; c) coordenação dos dias e alimentação, responsável por toda a organização do dia, ajudando inclusive a organizar a alimentação para o coletivo.

Essas comissões se reuniam, no início e ao final de cada módulo, para organizarem o encontro atual e planejarem o próximo. Cada coordenador desses grupos, se integravam à comissão político pedagógica do curso, formada pela representação dos cursistas, da Seme, Raceffaes, Efac, Emcors e Comec-NV, constituindo um espaço compartilhado de gestão do programa. 
Dessa forma, foi possível ir ajustando o programa aos anseios da Seme, do coletivo da Pedagogia da Alternância, mas principalmente às expectativas dos cursistas, se configurando como um importante espaço democrático de construção da formação.

Essa gestão e auto-organização foi construída na perspectiva proposta por Freire (2013, p. 10), “a prática da liberdade só encontrará adequada expressão numa pedagogia em que o oprimido tenha condições de, reflexivamente, descobrir-se e conquistar-se como sujeito da sua própria destinação histórica."

Em relação a cada encontro presencial, o mesmo foi dividido em quatro momentos. O primeiro deles e o último foram dedicados a mística e a gestão do curso, por meio da auto-organização do coletivo.

O segundo momento consistiu na socialização, pelos cursistas, da pesquisa do Plano de Estudo, seguida de debate e problematização, gerando pontos de aprofundamento, que foram abordados pelos assessores/as, por meio de palestras, debates, vídeos, leituras, etc, promovendo o aprofundamento teórico sobre a Pedagogia da Alternância e a Educação do Campo, encerrando o turno matutino.

O terceiro momento ocupou a maior parte do período vespertino, onde foram realizadas oficinas e trabalhos de grupo para diálogo e exercício prático sobre os aspectos abordados na parte teórica, encerrando essa atividade com um levantamento de proposições para as práticas nas escolas do campo. Ao final do dia, a formação foi encerrada com orientação das atividades para a estadia, auto-organização e mística.

O último encontro do curso foi realizado no formato de seminário, onde o evento foi aberto para outros segmentos da sociedade civil organizada, como os conselhos e associações de escola, associações de produtores/as rurais, órgãos de assistência técnica e extensão rural, movimentos e organizações sociais do campo e demais interessados na temática. $O$ intuito foi aproveitar o acúmulo dos educadores/as nesse processo de formação, a participação de outros sujeitos do campo e, dialogar sobre possibilidades de avanços na construção da Educação do Campo em Nova Venécia. 
Em relação aos desafios para operacionalização do curso, destacamos a questão da participação dos cursistas, pois, apesar da Seme ter autorizado a participação na formação, isso só foi possível para aqueles que trabalhavam integralmente nessa rede de ensino, tendo alguns, por esse motivo não conseguido participar integralmente do tempo presencial.

Além disso, a grande extensão territorial do município e a falta de logística de transporte, nem sempre possibilitou todo coletivo estar presente no início do curso e ao final, pois os horários de transporte nem sempre eram compatíveis para possibilitar o cumprimento da carga horária presencial. Algumas linhas foram garantidas pela Seme, mas outras não foram possíveis, ficando a cargo de cada educador/a se organizar para participar do curso.

A formação evidenciou ainda a necessidade de, em próximos momentos de formação, buscar alternativas para viabilizar, além do transporte, alimentação para os cursistas, pois, apesar da necessidade e interesse dos mesmos, muitos acabaram sendo onerados, tendo alguns inclusive contratado substituto para assumir sua função nas outras redes de ensino que atuavam.

Ainda com base nas avaliações e manifestações dos/as cursistas, além dos desafios, também foi possível constatar o valor da formação e a expectativa em relação às próximas. Para muitos/as, apesar de já atuarem em escolas do campo, não haviam participado de momentos específicos de formação para trabalharem nessa modalidade, sendo muito valorizada as oportunidades de aprendizagem de novas metodologias para sua prática cotidiana nas escolas, mas principalmente por possibilitar a reflexão sobre as especificidades do que é ser educador/a do campo e sobre as particularidades dos povos que ali habitam, exigindo uma postura diferente desse profissional frente a esse coletivo.

Para as Emcor's, o curso ajudou a iniciar o planejamento operacional de algumas atividades da Pedagogia da Alternância, que seguiu sendo elaborado e operacionalizado no âmbito das equipes no espaço da escola. Para a Efac, a oportunidade possibilitou conhecer com mais detalhes a experiência das escolas públicas da Pedagogia da Alternância, possibilitando aproximar sua prática dessa experiência. 
Diante da boa avaliação e dos apontamentos apresentados, a expectativa criada foi que no processo seletivo para 2019, o curso seria considerado como requisito no edital de seleção para as escolas do campo e que haveria nova turma. Contudo, nenhuma dessas expectativas se confirmaram.

Em 2020 esperava-se retomar o diálogo sobre a continuidade do Programa Girassol, mas, diante das limitações do coletivo da Pedagogia da Alternância, Educação do Campo, Seme e com o agravante da pandemia do novo Corona Vírus (Covid-19), não foi possível seguir com essa construção. Para 2021, logo que possível a retomada da normalidade cotidiana, o coletivo da Pedagogia da Alternância espera retomar com a gestão da Seme o processo de formação continuada de educadores/as do campo, pois acredita-se que as demandas apresentadas nos seminários e na avaliação do programa não foram suficientemente atendidas, permanecendo atuais.

\section{Considerações finais}

Diante do exposto, fica evidente que a formação dos educadores/as do campo se constituiu como um desafio histórico a esse coletivo no município de Nova Venécia, uma vez que a ausência de uma política pública para esse fim, deixa esses profissionais a mercê das prioridades e projetos de cada gestão do município.

Do mesmo modo, expresso pelo movimento estadual e nacional da Educação do Campo (RACEFFAES, 2015; ARROYO, 2007), a ausência de uma política de formação de educadores/as do campo, aprofunda as assimetrias educacionais entre os camponeses/as e, em relação aos citadinos, pois a formação é um direito e um dos pilares essenciais a construção da Educação do Campo, sendo que o educador/a assume significativo papel na construção da oportunidade ao direito à Educação do Campo, territorializada e atendendo aos interesses das famílias, como vimos anteriormente.

A ausência de uma política de formação para educadores/as das Emcor's, e das outras escolas que estão no campo e buscam se constituir como no e do campo, foi assunto inclusive do seminário municipal de Educação do Campo de Nova Venécia, onde dentre as diversas demandas apresentadas pelo coletivo, 
destacamos a necessidade de "Construir currículo adequado às escolas do campo; Utilizar metodologias adequadas aos estudantes e escolas do campo; Realizar formação específica sobre a Educação do Campo para os professores que atuam nesses territórios [...]" (PMNV, 2015, p. 2).

Para além da formação dos educadores/as, o programa, também possibilitou apontar demandas para a Seme e o coletivo da Educação do Campo de Nova Venécia. Para a Seme, a demanda se deu no sentido da continuidade de ações formativas, específicas para a Educação do Campo e também mudanças estruturais no Projeto Político e Pedagógico, para que as escolas tenham caráter de escolas do campo, caminhando para superar a forte característica, ainda presente, de escola para o campo.

Também foi ressaltada a pouca autonomia dos educadores/as em relação aos processos político-pedagógicos da escola, sendo esses muito dependentes da Seme.

Nesse sentido, foi apontado a necessidade de estabelecer setor de Educação do Campo dentro da Seme para articular processos de formação e acompanhamento das escolas do campo, contribuindo para a sua adaptação pedagógica.

Para o coletivo da Educação do Campo, ficou evidente o interesse da participação das outras escolas nesse movimento, ficando claro que a Educação do Campo em Nova Venécia, no sentido que os movimentos sociais acreditam e que apresentamos anteriormente nesse trabalho, ainda está em construção, sendo evidente a motivação das famílias e educadores/as em realizar o debate e a formação para alcançar esse ideal.

Também é notório que esse coletivo está para além das escolas da Pedagogia da Alternância, sendo necessário a esse grupo, compreender que o seu acúmulo histórico precisa ser colocado à disposição desse movimento, ajudando-o a seguir nessa caminhada.

Por todas essas questões, mas sem perder de vista as garantias legais para a formação de educadores/as, fica nítida a necessidade de um programa perene de formação de educadores/as para a Educação do Campo em Nova Venécia, contribuindo para o desenvolvimento das pessoas e do meio. 


\section{Referências}

ARROYO, M. G; CALDART, R. S; MOLINA, M. C. Por uma educação do campo. 3. ed. Petrópolis: Vozes, 2008.

ARROYO, M. G. Políticas de Formação de Educadores (a) do Campo. Cad.Cedes, Campinas, vol.27, n. 72, p.157-176, maio/ago. 2007. Disponível em: $<$ https://www.scielo.br/pdf/ccedes/v27n72/a04v2772.pdf >. Acesso em: 15 mai 2020.

BEGNAMI, J. B. Formação pedagógica de monitores das escolas famílias agrícolas e alternâncias: um estudo intensivo dos processos formativos de cinco monitores. Dissertação (Mestrado) - Universidade Nova de Lisboa/Universidade François Rabelais/UNEFAB. Brasília. 2003. Disponível em: $<$ https://run.unl.pt/bitstream/10362/391/1/begnami 2003.pdf $>$. Acesso em: 17 de jun 2020.

CALDART, R. S. Educação do Campo. In: CALDART, R. S. et al (Orgs.). DICIONÁRIO DA EDUCAÇÃO DO CAMPO. São Paulo: Expressão Popular, 2012. p. $259-267$.

Por Uma Educação do Campo: traços de uma identidade em construção. In: KOLLING, E. J.; CERIO-LI, P. R.; CALDART, R. S. (Org.). Educação do Campo: identidade e políticas públicas. Brasília, 2002. p. 18 -25.

EFAC - Escola Família Agrícola de Chapadinha. Expansão da Pedagogia da Alternância em Nova Venécia. Nova Venécia, 2010. (documento de circulação interna).

FOERSTE, E. Pedagogia da Terra: diálogos entre MST e universidade. In: $28^{a}$ Reunião Anual da Anped, Minas Gerais. Anais... Minas Gerais: Anped, 2005. Disponível em:< http://28reuniao.anped.org.br/ >. Acesso: 18 mai. 2020.

FRANÇA, J. V; BURGHGRAVE, T. A profissão de monitor (a) de CEFFA: a busca do reconhecimento. Revista da Formação por Alternância, Brasília, V. 2, n. 2, p. 39-46, ISSN1808-74043, 2007.

FREIRE, P. Pedagogia do oprimido. 17. Ed. Rio de Janeiro: Paz e Terra, 2013. GIL, A. C. (ORG). Delineamento da Pesquisa. 6. ed. São Paulo: Atlas, 2008. v. 6.

GIMONET, J. C. Praticar e compreender a pedagogia da alternância dos CEFFAs. Petrópolis: Vozes, 2007.

LEONARD, C. R; SIMÕES, R. D. Hisstória da licenciatura em educação do campo na Universidade Federal do Espírito Santo (Ufes). In: XII Congresso Nacional de Educação - EDUCERE. Paraná. p.11661-11668, ISSN2176-1396. Anais... Paraná: PUC. 2015. Disponível em: <https://educere.bruc.com.br/arquivo/pdf2015/19401_8274.pdf>. Acesso: 18 dez. 2018. 
NOSELLA, P. As Origens da Pedagogia da Alternância no Brasil. Coleção Educação do Campo, $2^{\mathrm{a}}$ Reimpressão, Vitória: EDUFES, 2014.

Militância e profissionalismo na educação do homem do campo.

Revista da Formação por Alternância, Brasília, V. 2, n. 2, p. 5-18, ISSN180874043, 2007.

OLIVEIRA, E. Da teoria à prática: um estudo de caso sobre o projeto profissional jovem da escola família agrícola de Jaguaré. 2018. 86f. Dissertação (Mestrado em Educação Agrícola) - Programa de Pós Graduação em Educação Agrícola, Universidade Federal Rural do Rio de Janeiro.

OLIVEIRA JÚNIOR, C. E. A Pedagogia da Alternância e a construção do conhecimento agroecológico no norte do estado do Espírito Santo: desafios e possibilidades. 2019, 275f. Dissertação (Mestrado em Educação) Programa de Pós-graduação em Educação Agrícola, Universidade Federal Rural do Rio de Janeiro, 2019.

PMNV - PREFITURA MUNICIPAL DE NOVA VENÉCIA. Ata do II Seminário de Educação do Campo de Nova Venécia. Nova Venécia - ES, 2015.

PPP. Proposta Político-Pedagógica do Programa Girassol de Formação Continuada de educadores/as para atuar na Educação do Campo e Pedagogia da Alternância. Nova Venécia, ES. 2018. 9 p.

RACEFFAES- Regional das Associações dos Centros Familiares de Formação em Alternância do Espírito Santo. Cultivando a educação dos povos do campo do Espírito Santo. Nova Venécia: Cricaré, 2015. 151 p.

A perspectiva de ser monitor nos Ceffa`s. Nova Venécia, 2010. (documento de circulação interna).

RODRIGUES, F. J. S. Rupturas e permanências no processo educativo dos centros familiares de formação em alternância - CEFFAS-ES: expansão da pedagogia da alternância no norte do estado do Espírito Santo. 2019, 211f. Dissertação (Mestrado) - Programa de Pós-graduação em Ensino na Educação Básica, Universidade Federal do Espírito Santo, 2019. Disponível em: <http://repositorio.ufes.br/handle/10/11059>. Acesso em: 15 mai. 2020.

\section{Sobre os autores}

Celso Eulálio de Oliveira Júnior

celsoeulalio@hotmail.com

Técnico em Agropecuária (EFAV, 2003); Licenciado em Ciências Agrícolas (UFRRJ, 2008); Aperfeiçoamento em Pedagogia do Alternância e Educação do Campo, (IFES, 2015); Mestre em Educação (UFRRJ, 2019); Professor/monitor na Escola Família Agrícola de Chapadinha (2009 a 2020); Membro da Regional 
das Associações dos Centros Familiares de Formação em Alternância do Espírito Santo (RACEFFAES, 2008 a 2020).

\section{Alcione Reetz}

alcionereetz@hotmail.com

Licencianda em História (UNIUBE, 2017); Membro da Regional das Associações dos Centros Familiares de Formação em Alternância do Espírito Santo (RACEFFAES , 2015 a 2020). 